\title{
PEDAGOGIA HOSPITALAR: O LÚDICO COMO UM CONSTRUCTO DA PSICOMOTRICIDADE
}

\author{
Cleysiele Ferreira Duarte, Universidade Federal de Campina Grande (UFCG), \\ gleyzieleduarte@gmail.com
}

PALAVRAS-CHAVE: Lúdico; Psicomotricidade; Pedagogia hospitalar.

\section{INTRODUÇÃO}

O presente texto trata-se do recorte de um estudo acerca da percepção sobre o impacto no processo de humanização e recuperação das crianças internadas no Hospital Universitário Júlio Bandeira- HUJB, por intermédio de atividades lúdicas. Sendo assim, é propósito deste apresentar reflexões acerca da contribuição do lúdico para o desenvolvimento da psicomotricidade na criança hospitalizada.

Desta forma buscamos compreender a realidade de crianças hospitalizadas, o valor da psicomotricidade aliada a atividades lúdicas e o papel do Pedagogo no processo de humanização e recuperação. Na sequência, buscamos reconhecer a prática do Pedagogo em unidades hospitalares, bem como, mapear os tipos de conhecimentos dos Pedagogos sobre psicomotricidade.

Partimos do pressuposto de que a relação (eu, coisas e o outro) é significativa para formação psíquica- afetiva - motora da criança. Nesse sentido, entende-se que o estudo aprofundado sobre Psicomotricidade seja relevante para propiciar a compreensão acerca da importância da experiência da criança com a manipulação de material concreto, o que de certo modo vem a contribuir no processo de humanização e recuperação da criança.

Sendo assim problematizamos, qual a contribuição do lúdico para o desenvolvimento da psicomotricidade? E qual o valor da psicomotricidade aliada às atividades lúdicas no atendimento à criança hospitalizada?

O lúdico pode contribuir significativamente no desenvolvimento da psicomotricidade Revista de Pesquisa Interdisciplinar, Cajazeiras, n. 2, suplementar, p. 829 - 833 set. de 2017. 
pois ele ativa os sentimentos de bem-estar na criança durante e após as atividades. Sendo assim, o trabalho do Pedagogo acontece como um impulsionador no processo de recuperação das crianças nesse processo de intermediação com as atividades. Nesse sentido, poderemos ter um olhar diferenciado durante as atividades, considerando que, pode contribuir significativamente para o desenvolvimento da psicomotricidade, levando- nos a pensar em atividades voltadas especificamente para o desenvolvimento desta, objetivando a recuperação da criança hospitalizada.

Desta forma a luz de alguns autores, tais como: Le Boulch (1984), Fonseca (2004), Levin (2000), Oliveira (1997), entre outros, buscaremos compreender o valor da psicomotricidade e suas contribuições no ambiente hospitalar.

\section{METODOLOGIA}

A coleta de dados deu-se por meio da TACDN (Tabela de Análise de Textos Acadêmicos e Científicos das Dimensões Novikoff) e da análise dos registros do relatório final do projeto de extensão, que aconteceu na vigência do ano de 2016 com a duração de um período. A exploração do material auxiliou na veracidade das interpretações e inferências, por isso consiste numa etapa muito importante; e podemos assim caracterizá-la como a parte da descrição analítica do material coletado o qual foi orientado pelas hipóteses e referenciais teóricos.

\section{O LÚDICO COMO UM CONSTRUCTO DA PSICOMOTRICIDADE}

Podemos considerar o lúdico e o trabalho pedagógico realizado pelo pedagogo uma importante ferramenta no trato da criança hospitalizada, favorecendo-a um ambiente agradável, fazendo-a esquecer de que está em um hospital e até mesmo doente.

Em relação aos sentimentos da criança no ambiente hospitalar afirma Latterza (2010, p.8) que "a arte humaniza o homem. Com arte você pode ousar mexer, brincar, sofrer, modificar, criar de novo, etc. A linguagem artística permite que a criança exteriorizar as 
emoções. Trabalha também a autoestima e a autoconfiança." Sendo assim, as atividades lúdicas, como teatro de fantoches, leitura infantil, livros sensoriais, etc., agem como importantes ferramentas que podem influenciar diretamente no emocional, contribuindo para a mudança de humor e na adaptação ao hospital. .

Nesse sentido, as atividades pedagógicas citadas possui um papel importante na assistência pedagógica à criança hospitalizada, bem como, para dissociá-la do ambiente a qual está, tirando assim o peso do ambiente considerado de dor e sofrimento, tanto para a criança quanto para os pais.

Podemos perceber assim, que as atividades lúdicas nos interiores dos hospitais podem contribuir consideravelmente para o desenvolvimento da psicomotricidade e na humanização das crianças hospitalizadas.

Segundo o Plano Nacional de Educação Infantil (2010, p. 53):

Quando uma criança brinca, ela entra em contato com suas fantasias, desejos e sentimentos, conhece a força e os limites do próprio corpo e estabelece relações de confiança com o outro. No momento em que está descobrindo o mundo, ao brincar testa suas habilidades e competências, aprende regras de convivência com outras crianças e com os adultos, desenvolve diversas linguagens e formas de expressão e amplia sua visão sobre o ambiente que a cerca.

Nesse sentido, podemos perceber o quanto é significativo às atividades lúdicas especificamente no ambiente hospitalar, as quais colaboram para uma integração das crianças internadas com outras crianças, com os funcionários, com o pedagogo e principalmente com o ambiente que a cerca, o que se constitui o mais difícil para a criança, devido ao seu estado doentio e pelo ambiente em si, que é não é muito agradável.

Nesse sentido, o pedagogo pode buscar diversos tipos de atividades que virão chamar atenção das crianças; a leitura de uma história, o uso de materiais pedagógicos, como, livros sensoriais, dados pedagógicos, jogo da memória, músicas infantis, entre outros; tudo depende da criatividade de cada um e do desprendimento em proporcionar alegria às crianças 
hospitalizadas.

A psicomotricidade está intimamente ligada a estas atividades, pois esta trabalha o movimento, domínio do corpo e a aquisição da linguagem verbal e escrita, por isso é importante antes de qualquer atividade conhecer um pouco da criança e as dificuldades que apresenta para que assim possa realizar a atividade adequada.

Sendo assim, o jogo é um importante recurso para estimular a criatividade e ajudar a criança emocionalmente o qual pode favorecer para que a criança pense logicamente, saiba se relacionar com outro, etc.

A psicomotricidade dá ao estudo do movimento humano uma dimensão mais científica trabalhando a linguagem, imagem do corpo, com os aspectos perceptivos gnósico e práxicos e toda uma rede interdisciplinar, promovendo um universo de reflexões no sentido de facilitar o desenvolvimento global do aluno/paciente permitindo que ele se expresse livremente no pensar e fazer. (LATTERZE, 2010, p.10)

Compreendemos assim, que o lúdico como um constructo da psicomotricidade pode auxiliar na socialização com os outros pacientes, com os profissionais, contribuindo para sua permanência e integração ao hospital, bem como a sua recuperação. Conforme afirma Kishimoto (1996, p.43), “[...] os jogos colaboram para a emergência do papel comunicativo da linguagem, a aprendizagem das convenções sociais e a aquisição das habilidades sociais".

\section{CONSIDERAÇÕES FINAIS}

Constatamos que a partir de atividades lúdicas diferenciadas o desenvolvimento das crianças é significativo, as quais mantém uma rotina cansativa no interior do hospital, podendo receber atividades diversificadas que lhe proporcione momentos de alegria e prazer, pela quebra de rotina, favorecendo na mudança de humor e no bem-estar, mesmo que em situação não muito agradável.

Outrossim, é imprescindível o uso da intencionalidade na execução das atividades, o que é preocupação deste trabalho mostrar que não é somente necessário proporcionar Revista de Pesquisa Interdisciplinar, Cajazeiras, n. 2, suplementar, p. 829 - 833 set. de 2017. 
momentos de alegria as crianças hospitalizadas, mas saber o que esta fazendo e quais impactos causam na criança.

Em suma percebemos a importância de se pensar no trabalho pedagógico do pedagogo em unidades hospitalares, para que assim haja o conhecimento dessas novas áreas, bem como, a valorização desse profissional.

\section{REFERÊNCIAS}

BRASIL. Lei 8.069, de 13 de julho de 1990. Dispõe sobre o Estatuto da Criança e do Adolescente e dá outras providências. Diário Oficial da União. Brasília, 13 de julho de 1990.

KISHIMOTO, Tizuko Morchida. O jogo, a criança e a educação. Petrópolis: Vozes, 1993.

LATTERZA, Eliane. A Importância da Psicomotricidade na Arteterapia em um Hospital Oncológico. São Paulo, p. 1-25, 2010.

MINISTÉRIO DA EDUCAÇÃO. Secretaria da Educação Infantil. Plano nacional de educação infantil. Brasília: MEC, 2010.

NOVIKOFF, C. Dimensões Novikoff: um constructo para o ensino-aprendizado da pesquisa. In ROCHA, J. G. e NOVIKOFF, C. (orgs.).Desafios da práxis educacional à promoção humana na contemporaneidade. Rio de Janeiro: Espalhafato Comunicação, p. 211-242, 2010a.

Metodologia da pesquisa científica. (Apostila de Metodologia da pesquisa Científica - Biblioteca Nacional). Rio de Janeiro, 2007.

As Representações Sociais Acerca do Ensino Superior para professores de graduação na área da saúde. Tese (Doutorado em Educação: Psicologia da Educação), Pontifícia Universidade Católica de São Paulo, São Paulo, 2006.

TASHAKKORI, A. \& TEDDLIE, C. Handbook of Mixed Methods in Social \& Behavioral Research. Thousand Oaks: Sage, 2003.

TRÉZ, Thales de A. e. Caracterizando o método misto de pesquisa na educação: um continuum entre a abordagem qualitativa e quantitativa. Atos de Pesquisa em Educação PPGE/ME, ISSN 1809-0354 v. 7, n. 4, p. 1132-1157, dez. 2012. 